\title{
Role of Exercise Echocardiography to Predict Coronary Artery Disease
}

\author{
PALLOB KUMAR BISWAS, FAKHRUL ISLAM KHALED, TANJIMA PARVIN, MANZOOR MAHMOOD, D.M.M \\ FARUQUE OSMANY, GOUTOM CHANDRA BHOWMIK, ABM GOLAM MOSTOFA, CHAYAN KUMAR SINGHA, \\ AHASANUL KABIR, SAJAL KRISHNA BANERJEE, CHAUDHURY MESHKAT AHMED \\ Department of Cardiology, Bangabandhu Sheikh Mujib Medical University (BSMMU), Dhaka \\ Address of Correspondence: Dr. Pallob Kumar Biswas, MD Student, Department of Cardiology, Bangabandhu Sheikh Mujib \\ Medical University (BSMMU), Dhaka. E-mail: k.pallobbiswas@gmail.com
}

\begin{abstract}
:
Background: Coronary artery disease (CAD) is predicted to be the most common cause of death globally. Early detection of coronary artery disease and adequate management can reduce CAD related morbidity and mortality. Various non-invasive procedures have been developed to diagnose CAD. Stress echocardiography, myocardial perfusion (SPECT) and cardiac MRI are accepted as useful tools for evaluation of inducible myocardial ischaemia in intermediate risk group patient documented by pre test probability. Among them exercise echocardiography is a remarkable physiological, safe, feasible and cost effective.
\end{abstract}

Objective: To see the role of exercise echocardiography to predict CAD.

Materials and methods: This cross sectional study was conducted in University Cardiac Center (UCC), BSMMU. This study include the patients who are appointed for exercise tolerance test (ETT). Echocardiographic wall motion study was recorded at rest and after peak exercise and analyzed to diagnosis the regional wall motion abnormality. Specific CAD was confirmed by coronary angiogram.

Results: A total of 40 patients were included in the study from the patients who are appointed for ETT. Patients diagnosed as $C A D$ has the mean age of $50.6 \pm 9.7$ years and majority of the patients were male (72.5\%). Sensitivity, specificity, positive predictive value and negative predictive value of exercise echocardiography were $85.5 \%, 76.9 \%, 88.5 \%$ and $71.4 \%$ respectively in predicting coronary artery disease by exercise echocardiography. The predominant risk factors was hypertension (40.0\%) followed by diabetes mellitus, smoking, dyslipidaemia and family $\mathrm{H} / \mathrm{O} C A D$ were significantly associated with the development of CAD in the study subjects.

Conclusion: Treadmill exercise stress echocardiography demonstrates high significance for diagnosis of CAD.

Keywords: Coronary artery disease, Inducible Myocardial Ischaemia, Exercise Stress Echocardiography, Exercise Tolerance Test.

University Heart Journal 2021; 17(2): 114-117

Introduction:

Cardiovascular disease (CVDs) is the leading causes of death globally. In Bangladesh recent data indicates coronary artery disease prevalence was in between $2.7 \%$ and $3.4 \%$ in rural population and $19.6 \%$ in urban working professionals. ${ }^{1}$ Early detection of coronary artery disease and adequate management can reduce CAD related morbidity and mortality

Coronary angiogram remains the gold standard for diagnosing CAD. However, angiographically normal coronary arteries are found in $20-30 \%$ cases among the coronary angiography done for chest pain evaluation. ${ }^{2}$
So, an appropriate noninvasive investigation for diagnosis of CAD can help early detection of CAD and initiation of treatment quickly.

Various non-invasive procedures have been developed to diagnose coronary artery disease. Different stress modalities are in practice at present like ETT, DSE, MPI and CT angiogram. ETT has gained wide acceptance and application in identifying coronary artery disease. Exercise stress echocardiography has more specificity than ETT to diagnose CAD incase of unfavourable ECG (Digoxin use, LVH with repolarization abnormalities, preexcitation or bundle branch block) ${ }^{3}$ women ${ }^{4}$ and both normo and hypertensive patients. ${ }^{5}$ 
The diagnostic specificity of exercise ECG and MPI is definitely lower in women due to hormonal influences for exercise testing and breast attenuation for nuclear technique.DSE is inferior to exercise for producing physiological stress. MPI is available in very few centres and are expensive. Exercise stress echocardiography provides similar diagnostic and prognostic accuracy as MPI or MRI but at a substantially lower cost, without environmental impact and no radiation hazards for the patient and the physician.

Treadmill exercise stress echocardiography have high significance for diagnosis of CAD with high negative predictive value, it can help deciding appropriate case selection for CAG.

Despite the validity of exercise echocardiography, exercise stress echocardiography have not reached a full blown status and not known to be used on a routine clinical basis and it has not been used widely in our country. The gap of knowledge of utility of exercise echocardiography should be filled with prospective studies to support more evidence based treatment strategies in our country.

\section{Materials and Methods:}

This study was conducted in the Department of Cardiology, BSMMU, DHAKA. Study period was from April 2019September 2019. It was a cross sectional observational study. The study was carried out in patients who underwent exercise stress test for detection of inducible myocardial ischaemia.

Patients underwent exercise tolerance test (ETT) for detection of inducible myocardial ischemia and who were agreed to do CAG was included. Patients having structural heart disease, valvular heart disease, congenital heart disease, hypertrophic cardiomyopathy, old MI, left ventricular dysfunction (an ejection fraction $<50 \%$ ) and who can not perform treadmill exercise, having ETT contraindication and echocardiography window poor was excluded.

Selection of study population from those patients underwent ETT after meeting inclusion and exclusion criteria. At first resting echocardiography showed no regional wall motion abnormality, then treadmill ECG was done. Treadmill echocardiography and wall motion study was done in ETT positive patients within 1-1.5 minutes of peak exercise by expertise. Coronary angiography was done in echocardiography positive and negative patients.

Continuous variables was expressed as means \pm SDs and categorical variables was expressed as percentages. Correlation of stress Echo findings with CAG findings was done. Concordance in coronary artery territory between induced ischemia during treadmill exercise stress echocardiography and coronary artery disease on coronary angiography was analyzed by two by two contingency table. A $p<0.05$ will be used to reject the null hypothesis. The statistical analysis will be performed using Statistical Package for the Social Sciences (SPSS) version 22 (SPSS Inc., Chicago, IL, USA).

\section{Results:}

More than half $(52.5 \%)$ of the patients were upper middle aged or elderly ( 50 or $>50$ years old), 35\% middle aged (4150 years) \& only $12.5 \%$ lower middle aged ( $<40$ years). The mean age of the patients were $50.6 \pm 9.7$ years. Patients were predominantly male $(72.5 \%)$ with male to female ratio roughly being $2.6: 1$. (Table I)

\section{Table I}

Distribution of patients by their demographic characteristics $(N=40)$

\begin{tabular}{lcc}
\hline Age (years) & Frequency $(\mathrm{n})$ & Percentage \\
\hline$\leq 40$ & 5 & 12.5 \\
$41-50$ & 14 & 35.0 \\
$51-60$ & 14 & 35.0 \\
$>60$ & 7 & 17.5 \\
Male & 28 & $72 \%$ \\
Female & 12 & $28 \%$ \\
\hline
\end{tabular}

Mean $\pm \mathrm{SD}=50.6 \pm 9.7$

There is no regional wall motion abnormality before exercise but after exercise wall motion abnormality present. As $\mathrm{P}$ value is $<0.001$, so the result is significant.(Table II)

Table II

Pre and post exercise wall motion score and index $(N=40)$

\begin{tabular}{cccc}
\hline & Pre & Post & p-value \\
\hline Total wall motion score & $17.00 \pm 0.00$ & $22.47 \pm 1.48$ & $<0.001$ \\
Wall motion score index & $1.00 \pm 0.00$ & $1.32 \pm 0.08$ & $<0.001$ \\
\hline
\end{tabular}

Highest proportion of inducible ischaemia was observed in RCA territory (65\%), followed by LCX territory (35\%) \& LAD territory $(25 \%)$. (Table III)

\section{Table III}

Distribution of arterial territorial involvement in individuals with inducible myocardial ischaemia by exercise stress echocardiography $(N=40)$.

\begin{tabular}{lcc}
\hline $\begin{array}{l}\text { Inducible myocardial } \\
\text { Ischaemia }\end{array}$ & Frequency $(\mathrm{n})$ & Percentage \\
\hline LAD territory & 10 & 25.0 \\
RCA territory & 26 & 65.0 \\
LCX territory & 14 & 35.0 \\
\hline
\end{tabular}


Sensitivity, specificity, positive predictive value \& negative predictive value of exercise echocardiography were $85.2 \%$, $76.9 \%, 88.5 \%$ \& $71.4 \%$ respectively in predicting coronary artery disease.(Table IV)

\section{Table-IV}

Predictive value of exercise echocardiography for diagnosis coronary artery disease of the study population $(N=40)$

\begin{tabular}{lccc}
\hline Exercise echo & CAG & Total & \\
\hline & Positive & Negative & \\
Positive & $23(85.2)$ & $3(23.1)$ & $26(65.0)$ \\
Negative & $4(14.8)$ & $10(76.9)$ & $14(35.0)$ \\
\hline Total & $27(100.0)$ & $13(100.0)$ & $40(100.0)$ \\
\hline
\end{tabular}

$\mathrm{N}=$ number of study population

Validity test of exercise echo

\begin{tabular}{lc}
\hline & $\%$ \\
\hline Sensitivity & 85.2 \\
Specificity & 76.9 \\
Positive predictive value & 88.5 \\
Negative predictive value & 71.4 \\
\hline
\end{tabular}

\section{Discussion:}

In this study, the mean age of this study subjects was lower as compared with American and European studies. The highest proportion of patients were in the $4^{\text {th }}$ and $5^{\text {th }}$ decade in life. Increased occurance of CAD in this age group may be explained by increased prevalence of diabetes, dyslipidaemia and family history of CAD in younger population in our country.

Study performed in Asian, American and European population, the mean age of CAD was $47.43 \pm 9.58$ years $^{6}$, $56 \pm 10$ years ${ }^{7}$ and $61.0 \pm 12.3$ years ${ }^{8}$ respectively. The age variation for the development of CAD may be attributed to geographical variation and ethnic variation.

In this study, CAD occurred at a disproportionately high rate among male as compared with female. A study was performed showed $67.1 \%$ of them were male. ${ }^{9}$ Another study was performed showed $83.3 \%$ of them were male. ${ }^{10}$ However, the reason for male predominance in this study can be explained as females are reluctant to be treated due to socio-cultural and religious reason and oestrogen has got protective role for coronary artery disease in female.

In this study, sensitivity, specificity, positive predictive value and negative predictive value of exercise echo were $85.2 \%, 76.9 \%, 88.5 \%$ and $71.4 \%$ respectively in predicting coronary artery disease. This study results concurrent with the following study.
Kim et al. (2016) ${ }^{11}$ found sensitivity $70.4 \%$ and specificity $94.6 \%$ of exercise echocardiography in detection of coronary artery stenosis in women. Pasierski et al. $(2001)^{9}$ revealed sensitivity, specificity, positive predictive value and negative predictive value of exercise echocardiography were $82.0 \%$, $96.0 \%, 97.0 \%$ and $79.0 \%$ respectively in diagnosis of coronary artery disease. Kwok et al. (1999) ${ }^{12}$ reviewed exercise testing to detect coronary artery disease, they found sensitivity $86.0 \%$ and specificity $79.0 \%$ in their meta analysis. Limacher et al. (1983) ${ }^{13}$ studied 73 patients and showed that exercise echocardiography had $91.0 \%$ sensitivity and $88.0 \%$ specificity in predicting coronary artery disease. Armstrong et al. (1986) ${ }^{14}$ tested 95 patients with known and suspected coronary artery disease and revealed that exercise echocardiography had $88.0 \%$ sensitivity and $87.0 \%$ specificity in predicting coronary artery disease.

Rayan et al. (1988) ${ }^{15}$ examined 64 patients with known and suspected coronary artery disease and found that exercise echocardiography had $78.0 \%$ sensitivity and 100.0\% specificity in predicting coronary artery disease. Sensitivity was $97.0 \%$ and specificity was $64.0 \%$ of exercise echocardiography in the study of Crouse et al. (1991) ${ }^{16}$ where 228 patients were enrolled. Quinones et al. (1992) ${ }^{17}$ conducted a study where they enrolled 289 patients with known or suspected coronary artery disease, in their study they found sensitivity $74.0 \%$ and specificity $88.0 \%$ of exercise echocardiography on prediction of coronary artery disease.

Marwick et al. (1992) 4 enrolled 179 patients with known or suspected coronary artery disease. Exercise echocardiography was performed on all the patients. They revealed that $84.0 \%$ sensitivity and $86.0 \%$ specificity of exercise echocardiography in diagnosis of coronary artery disease.

Our study reveals sensitivity, specificity, positive predictive value and negative predictive value of exercise echocardiography in prediction of coronary disease of patients as a whole.

\section{Conclusion:}

A significant proportion of patients with chest pain have underlying inducible myocardial ischaemia as evident by Exercise Stress Echocardiography. It may be more helpful to predict coronary artery disease by exercise stress echocardiography.

\section{Limitations:}

1. Single centered study.

2. Potential selection bias because only patients with chest pain were selected, a significant number of patients were left out. 
3. The study followed a cross-sectional design, so the patients were not followed up for clinical and prognostic parameter.

\section{Conflict of Interest:}

Authors has no conflict of interest.

\section{Acknowledgement:}

This study was a postgraduate thesis. The authors would like to thank all of the patients who enrolled in this study and staff of the Department of Cardiology, University Cardiac Center, Bangabandhu Sheikh Mujib Medical University, Dhaka, Bangladesh. Financial support was given by thesis grant of the Bangabandhu Sheikh Mujib Medical University, Dhaka, Bangladesh.

\section{References:}

1. Saquib N, Saquib J, Ahmed T, Khanam MA, Cullen MR. Cardiovascular diseases and type 2 diabetes in Bangladesh: a systematic review and meta-analysis of studies between 1995 and 2010. BMC public health. 2012 Dec 1;12(1):434.

2. Mukerji V, Beitman BD, Alpert MA. Chest pain and angiographically normal coronary arteries. Implications for treatment. Texas Heart Institute Journal. 1993;20(3):170.

3. Stnescu C. Exercise echocardiography in coronary artery disease. Romanian journal of internal medicine $=$ Revue roumaine de medecine interne. 2004;42(3):473-89.

4. Marwick TH, Anderson T, Williams MJ, Haluska B, Melin JA, Pashkow F, Thomas JD. Exercise echocardiography is an accurate and cost-efficient technique for detection of coronary artery disease in women. Journal of the American College of Cardiology. 1995 Aug 1;26(2):335-41.

5. Maltagliati A, Berti M, Muratori M, Tamborini G, Zavalloni D, Berna G, Pepi M. Exercise echocardiography versus exercise electrocardiography in the diagnosis of coronary artery disease in hypertension. American journal of hypertension. $2000 \mathrm{Jul}$ $1 ; 13(7): 796-801$.

6. Ali SI. Prioritizing patients for coronary angiography using simplified treadmill score in high risk Asian subjects in Saudi Arabia. PAKISTAN JOURNAL OF MEDICAL SCIENCES. 2006;22(2):122.

7. Morise AP, Olson MB, Merz CN, Mankad S, Rogers WJ, Pepine CJ, Reis SE, Sharaf BL, Sopko G, Smith K, Pohost GM. Validation of the accuracy of pretest and exercise test scores in women with a low prevalence of coronary disease: the NHLBI-sponsored Women's Ischemia Syndrome Evaluation (WISE) study. American heart journal. 2004 Jun 1;147(6):1085-92.

8. Papachristidis A, Roper D, Demarco DC, Tsironis I, Papitsas M, Byrne J, Alfakih K, Monaghan MJ. The prognostic role of stress echocardiography in a contemporary population and the clinical significance of limited apical ischaemia. Echo research and practice. 2016 Dec 1;3(4):105-13.

9. Pasierski T, Szwed H, Malczewska B, Firek B, Ko[micki M, Rewicki M, Kowalik I, Sadowski Z. Advantages of exercise echocardiography in comparison to dobutamine echocardiography in the diagnosis of coronary artery disease in hypertensive subjects. Journal of human hypertension. 2001 Nov;15(11):805-09.

10. Robertson WS, Feigenbaum H, Armstrong WF, Dillon JC, O'Donnell J, Mchenry PW. Exercise echocardiography: a clinically practical addition in the evaluation of coronary artery disease. Journal of the American College of Cardiology. 1983 Dec 1;2(6):1085-91.

11. Kim MN, Kim SA, Kim YH, Hong SJ, Park SM, Shin MS, Kim MA, Hong KS, Shin GJ, Shim WJ. Head to head comparison of stress echocardiography with exercise electrocardiography for the detection of coronary artery stenosis in women. Journal of cardiovascular ultrasound. 2016 Jun 1;24(2): 135-43.

12. Kwok Y, Kim C, Grady D, Segal M, Redberg R. Meta-analysis of exercise testing to detect coronary artery disease in women. The American journal of cardiology. 1999 Mar 1;83(5): 660-66.

13. Limacher MC, Quiñones MA, Poliner LR, Nelson JG, Winters Jr WL, Waggoner AD. Detection of coronary artery disease with exercise two-dimensional echocardiography. Description of a clinically applicable method and comparison with radionuclide ventriculography. Circulation. 1983 Jun; 67(6): 1211-18.

14. ARMSTRONG WF, O'DONNELL JA, DILLON JC, McHENRY PL, MORRIS SN, Feigenbaum H. Complementary value of two-dimensional exercise echocardiography to routine treadmill exercise testing. Annals of Internal Medicine. 1986 Dec 1;105(6):829-35.

15. Ryan T, Vasey CG, Presti CF, O'Donnell JA, Feigenbaum H, Armstrong WF. Exercise echocardiography: detection of coronary artery disease in patients with normal left ventricular wall motion at rest. Journal of the American College of Cardiology. 1988 May 1;11(5):993-99.

16. Crouse LJ, Harbrecht JJ, Vacek JL, Rosamond TL, Kramer $\mathrm{PH}$. Exercise echocardiography as a screening test for coronary artery disease and correlation with coronary arteriography. The American journal of cardiology. 1991 Jun 1;67(15):1213-18.

17. Quiñones MA, Verani MS, Haichin RM, Mahmarian JJ, Suarez J, Zoghbi WA. Exercise echocardiography versus 201Tl singlephoton emission computed tomography in evaluation of coronary artery disease. Analysis of 292 patients. Circulation. 1992 Mar;85(3):1026-31. 